\title{
Rim current and coastal eddy mechanisms in an eddy-resolving Black Sea general circulation model
}

\author{
Joanna V. Staneva ${ }^{\mathrm{a}, *, 1}$, David E. Dietrich ${ }^{\mathrm{b}}$, Emil V. Stanev ${ }^{\mathrm{c}, 2}$, Malcolm J. Bowman ${ }^{\mathrm{d}}$ \\ ${ }^{a}$ National Institute of Hydrology and Meteorology, Sofia, Bulgaria \\ b Department of Mechanical Engineering, University of New Mexico, Albuquerque, NM, USA \\ ${ }^{\mathrm{c}}$ Department of Meteorology and Geophysics, University of Sofia, Sofia, Bulgaria \\ ${ }^{\mathrm{d}}$ Marine Sciences Research Center, State University of New York, Stony Brook, NY, USA
}

Received 17 January 2000; accepted 9 March 2001

\begin{abstract}
The DieCAST ocean model is applied to a study of the circulation in the Black Sea, using $1 / 12^{\circ}$ horizontal resolution and with 20 vertical layers. Boundary forcings are monthly wind stress, evaporation minus precipitation, air-sea heat flux, freshwater influx from 11 rivers and exchange with the Mediterranean Sea through the Bosphorus Strait.

The model reproduces fundamental physical features of the Black Sea: seasonal fluctuations in the quasi-permanent cyclonic Rim Current, numerous anticyclonic meanders and eddies lying between the Rim Current and the coast, Rossby waves propagating westward across the basin, coastally trapped waves, and the annual cycle of vertical mixing. Model results shed light on the mechanisms affecting such features. These include interactions of the Rim Current with coastal bathymetry abutments, leading to recirculations that pinch off vortices as in island wakes, and possible baroclinic instability of the Rim Current; these are modulated by the large annual stratification cycle above a relatively shallow and strong pycnocline, as is the Rim Current itself. The resulting wake eddies often merge into major coastal circulation features such as the seasonal Batumi and Sevastopol eddies. These anticyclonic eddies play a fundamental role in coastal and open-sea exchange processes. Hydrographic data from sampling cruises and recent Topex-Poseiden $(T / P)$ altimeter data strongly supports our analysis. (C) 2001 Elsevier Science B.V. All rights reserved.
\end{abstract}

Keywords: Coastal eddies; Vorticity balance; Modelling

\section{Introduction}

The high resolution of recent oceanographic surveys (e.g., Aubrey et al., 1993; Oguz et al., 1993;

\footnotetext{
* Corresponding author. Department of Meteorology and Geophysics, University of Sofia, 5 James Bourchier Street, 1126 Sofia, Bulgaria. Tel.: +359-2-625-6289; fax: +359-2-962-5276.

E-mail address: joana@phys.uni-sofia.bg (J.V. Staneva).

${ }^{1}$ Present affiliation: Alfred-Wegener-Institut, Bremerhaven, Germany.

${ }^{2}$ Present affiliation: ICBM, University of Oldenburg, Germany.
}

Oguz et al., 1994), model simulations (e.g., Stanev, 1990; Oguz et al., 1995; Stanev and Staneva, 2000; Stanev and Beckers, 1999) and satellite data (Sur et al., 1994; Korotaev et al., 1998; Stanev et al., 2000, 2001), have added significant details to our knowledge of the Black Sea circulation. Vigorous mesoscale eddies, meanders and filaments have been revealed which pinch off coastal recirculation regions or Rim Current intrusions towards deep water. For example, several anticyclonic eddies have been observed, located between the Rim Current and the coast; east of Synop, along the Crimean Peninsula, 
and close to the Bosphorus region. The most prominent sub-basin scale feature is perhaps the quasi-permanent Batumi eddy located in the easternmost basin of the Black Sea.

Spatially and temporally evolving meanders and sub-basin scale eddies typically have wavelengths $\sim 125 \mathrm{~km}$ along the western and southern coasts, and $\sim 250 \mathrm{~km}$ along the northern coast (Oguz et al., 1994; Demishev, 1996; Stanev and Rachev, 1999). These scales are consistent with those estimated in earlier theoretical studies (e.g., Blatov et al., 1984). The density of existing survey data is still insufficient for a detailed understanding of the mechanisms of eddy formation. We will demonstrate in this paper that numerical simulations can add significant new information to our understanding of eddy genesis, transport and decay.

As well as the sub-basin scale eddies, small elongated anticyclonic eddies lodged between the Black Sea Rim Current (shelfbreak gyre) and the coast are of critical importance for the ventilation of the coastal seas (Ovchinnikov, 1998). These small-scale (10-50 $\mathrm{km})$ eddies involve coastal abutment wake recirculations similar to Von Karman vortex streets behind islands (e.g., Dietrich et al., 1997) and are high Reynolds number phenomena. Such coastal eddies are difficult to simulate in a full basin Black Sea model; even with the $1 / 12^{\circ}$ resolution used in this study, they are only marginally resolved. To our knowledge, no extensive analyses of coastal eddy dynamics have been carried out in previous Black Sea modeling studies; neither has the performance of contemporary numerical models been evaluated for their skill in simulating the major quasi-permanent Batumi and Sevastopol eddies.

This contribution aims to demonstrate that by using a very low dissipation model, adapted to the Black Sea environment, one can realistically simulate a large spectrum of mesoscale processes. Our aim is not to describe yet another new model of the Black Sea, but rather to present new results obtained from the DieCAST model running robustly with very low dissipation, fully fourth-order low-dispersion numerics and unfiltered shelfbreak bathymetry. Such accurate, low dissipation numerics is required in order to simulate the marginally resolved high Reynolds number shelfbreak Rim Current and coastal eddies that dominate the Black Sea general circula- tion. Bathymetry filters as used in some models would result in underprediction of the intensity of the Rim Current. This in turn would result in weakened anticyclogenesis as the diminished Rim current interacts with the filtered bathymetry and smoothed coastal abutments.

In Section 2, we briefly describe the numerical model, its boundary and initial conditions. Model results are described in Section 3. There, we compare model simulations with hydrographic survey and satellite data. Along with a discussion of the role that mesoscale eddies play in lateral exchange and pycnocline ventilation, we compare model simulations with existing hydrographic survey and satellite data. In Section 4, we analyze the details of the development and evolution of the most significant coastal eddies including the Batumi and Crimean eddies. The paper ends with a short conclusion.

\section{The DieCAST Model}

The DieCAST ocean model (Dietrich, 1997; http://www.ssc.erc.msstate.edu/DieCAST/) used in this study is a $z$-level, primitive, hydrostatic, Boussinesq, finite difference model running with very low dissipation and fully fourth-order numerics. The equations used are given in Appendix A.

With careful consideration of inflow and outflow characteristics and development of the cold intermediate layer (CIL) water mass in winter, the DieCAST model produces apparently realistic coastal dynamics even in regions of tortuous bathymetry (Sheng et al., 1998). The model uses a rigid-lid approximation. For the slow modes that dominate the general ocean circulation, the surface elevation field may be derived hydrostatically from the model-determined sea-surface pressure at the rigid lid. The rigid-lid approximation does not affect internal gravity wave speeds. Thus, it does not affect geostrophic adjustment of the baroclinic mode that dominates the general circulation. The barotropic mode adjustment involves fast high frequency surface gravity waves. The dominant time scales of the wind forcing are much longer, so the barotropic mode is nearly always near $q-g$ balance. The rigid-lid approximation may also simplify the treatment of open boundaries 
because it greatly reduces the range of frequencies that must be addressed. The Orlansky-like radiative approximation is excellent when dealing with a single dominant phase speed, but is not simple when a wide range of phase speeds must be addressed. Simple upwind open boundary treatment works nicely for some models, including DieCAST (Dietrich et al., 1997).

Fourth-order-accurate control volume approximations (Sanderson, 1998; Sanderson and Brassington, 1998) are used for all advection and horizontal pressure gradient terms, except adjacent to boundaries where second-order accuracy is used.

The model-predicted quantities are control-volume averages of horizontal momentum, potential temperature and salinity. Vertical velocity is derived from the incompressibility condition after first calculating the horizontal velocity in a manner such that the divergence of its barotropic mode matches that implied by a specified vertical velocity at the model surface. This surface vertical velocity is derived from a combination of net evaporation minus precipitation $(E-P)$ and input of freshwater from river sources located around the basin perimeter. A non-zero bottom vertical velocity derived from near-bottom horizontal velocity along the depth gradient could be included; there one has to be careful about conservation and incompressibility consistency. Instead, we assume zero velocity at the sloping bottom.

Such a barotropic mode specification implies some weak vortex stretching, but that is the long-term condition in nature. In the inviscid limit, even weak vortex stretching has significant effects in the long run because of spin-up of the net lateral inflow or outflow needed to maintain the surface level. The barotropic mode condition requires that the pressure at the model rigid-lid satisfies a Poisson equation derived from the incompressibility and horizontal momentum equations. The hydrostatic equation then determines pressure everywhere else, and may also be used to determine the hydrostatically equivalent free-surface height (e.g., Dietrich et al., 1987).

The Poisson equation is solved by an efficient EVP elliptic solver (Roache, 1995; Dietrich et al., 1975; Dietrich, 1981). Density is determined from a nonlinear equation of state relating density to potential temperature, salinity and pressure (courtesy D. Wright, Bedford Inst., Canada).
The incompressibility condition is applied to velocity components at control volume faces, thus requiring interpolation of nearby control-volume averaged velocities to the cell faces before adjustment. Fourth-order-accurate interpolations are used. The incompressibility adjustments are then communicated back to the "a" grid, again using fourth-orderaccurate interpolations (Dietrich, 1997). The Coriolis terms are evaluated on the "a" grid, thus having no spatial interpolation error, which is a significant advantage for such a dominant term.

All control volumes are collocated (viz., momentum, energy, salinity and the incompressibility approximation to mass conservation are all applied on the same control volume grid). The fundamental control-volume approach can be derived by integrating the conservative form of the continuum equations within specified control volumes. Generally, the control volume equations for momentum, energy and salinity involve fluxes across the specified control volume boundaries (i.e., the faces of control volume "boxes"). Most ocean models use a control volume approximation having different control volumes for horizontal momentum than those used for pressure, temperature salinity and other scalars. DieCAST control volumes are the same (nonstaggered, i.e. "collocated") for all variables, so the control volume equations for all quantities to which conservation laws are applied relate to the same control volume grid and to the associated single set of metrics, which is simpler, allows smaller numerical dispersion (Dietrich, 1997) and has other advantages compared to staggered grid approaches.

\subsection{Model adaptation to Black Sea, boundary condi- tions and parameters}

The horizontal resolution is $1 / 12^{\circ}$ (5 nautical miles). The model has 20 vertical layers, with interface depths at $0,10,23,38,56,78,105,136,174$, 220, 275, 340, 420, 515, 629, 767, 932, 1130, 1370, 1660 and $2000 \mathrm{~m}$. Bathymetry is unfiltered ETOPO 5 (NOAA, 1988), fitted to the nearest model $z$-level. Surface heating and wind stress, net evaporation minus precipitation $(E-P)$ and freshwater fluxes from 11 rivers around the perimeter of the Black Sea are specified from climatological data sets (Staneva and Stanev, 1998). The sea floor is insulated and non-slip as parameterized by a quadratic bottom drag 
coefficient of 0.002 . Bottom drag includes all momentum exchanges with the rigid bottom boundary; lateral exchanges at vertical boundary faces are ignored.

Significant exchange with the Mediterranean Sea occurs through the Bosphorus Strait. There is a net volume outflow from the Black Sea equal to the net input from rivers and $E-P$. The mixing processes of the Bosphorus Strait and the bottom density current entering the Black Sea are not resolved in this study. Thus, this exchange is already partially mixed at the inflow. Mediterranean Sea water of 35.75 psu is mixed with surface Black Sea water of 18 to give a mixture of $\sim 27.5 \mathrm{psu}$ in-flowing at depth in the Bosphorus Strait, and $\sim 22$ psu water outflowing near the surface. This exchange is spread over five horizontal and five vertical grid points at the confluence of the Bosphorus Strait with the Black Sea. The higher salinity modified Mediterranean water enters at layer 5 (between 56 and $78 \mathrm{~m}$ ). Lower salinity Black Sea water flows out in the top two layers (between 0 and $23 \mathrm{~m}$ ); to conserve water, the difference in transport matches the Black Sea net input of freshwater. Thus, the total salt content of the Black Sea is conserved.

Horizontal viscosity and diffusivity are set to a constant value of $10 \mathrm{~m}^{2} \mathrm{~s}^{-1}$. Vertical viscosity and diffusivity are set as the sum of three terms which parameterize laminar diffusivity and vertical Reynolds stresses as proposed by Pacanowski and Philander (1981; see Appendix B).

A biharmonic filter is applied to the velocity at the shelf break near the Bosphorus inflow. The purpose of the filter is to selectively damp poorly resolved small-scale turbulence that may have unphysical effects such as excessive vertical mixing. The strongest filtering is at layer 5 , with no filtering at the very stable levels above the inflow. The filter strength decreases rapidly away from the Bosphorus inflow shelfbreak location. At its location of maximum strength (level 5 at the mouth of the Bosphorus), the filter is such that it dissipates a twogrid-interval feature by $5 \%$ per model time step. The filtering rate coefficient is rapidly reduced over a distance of five grid intervals, (by a factor of 25) and the filter is not applied at larger distances.

The forcing of the model includes only the monthly variability of atmospheric variables derived from the climatic handbook edited by Sorkina (1974). This data set originates from coastal and ship measurements (in total 67,000 measurements). River discharges from the main rivers in the Black Sea (i.e. Danube, Dnepr and Dnestr) are also prescribed, using the monthly mean climatic data of Altman and Kumish (1986). Momentum fluxes are also computed from the climatological monthly data sets and are interpolated at each time step. The procedure of calculation of the wind stress is described by Staneva and Stanev (1998).

The model is initialized at a state of rest with annual mean temperature and salinity fields taken from the climatological data. The spin-up phase of integration is carried out for 15 years.

\section{Verifications of model results}

\subsection{The Black Sea modeling challenge}

The Rim Current, one of the most conspicuous and interesting physical phenomena of the Black Sea, is a narrow counter-clockwise flowing, basinwide current associated with at least two dominant physical characteristics: strong vertical and horizontal density gradients; and a narrow, steep, continental slope. Filtering bathymetry or using large dissipation to ensure numerical stability will decrease the Rim Current intensity. Such weakened Rim Current gradients in turn will lead to a reduced interaction with the smoothed bathymetry, which may eliminate the important coastal eddies altogether, thereby affecting the dynamics of the entire Black Sea. During weak winter stratification, the Rim Current interactions with fine-scale coastal abutments can be intense as a reduced Rossby radius of deformation causes the Rim Current to hug the shelf break. Thus, realistic, eddy resolving Black Sea models must: (i) completely resolve steep bathymetry; (ii) correctly simulate the annual cycle of stratification; and (iii) adequately simulate and/or parameterize shallow coastal zone processes having short length and time scales. Temporal variability, in particular that associated with mesoscale eddies, has yet to be adequately addressed. 
Several numerical models of the Black Sea satisfy condition (i) by using a variable resolution grid. As examples, Oguz et al. (1995) employed the Princeton Ocean Model (POM; Blumberg and Mellor, 1987). Beckers et al. (2001) adapted the GHER double $\sigma$-coordinate model (Nihoul et al., 1989; Beckers, 1991) with constant $5 \mathrm{~km}$ resolution over the entire Black Sea. Both models satisfactorily resolved the narrow continental slope in the southern Black Sea; however, in both models, results have not been adequately compared with observational hydrographic data.

Staneva and Stanev (1997) and Stanev and Staneva (2000) used the Modular Ocean Model (MOM; Pakanowski et al., 1991; / http://www.gfdl.gov/ $\sim$ kd/MOMwebpages /MOMWWW.html $)$, running at $1 / 12^{\circ}(\sim 9 \mathrm{~km})$ horizontal resolution with 24 vertical levels, to replicate quite accurately the formation of the wintertime intermediate water. However, the Rim Current was more diffuse and the coastal anticyclones produced were larger than found in nature. A number of other studies barely satisfy conditions (i) and (ii), but more importantly do not satisfy condition (iii), leading to inconsistencies in coastal eddy structure and behavior (e.g., see Gent and McWilliams, 1990). In this paper, we present modeling results which we believe overcome many of the above problems, especially those resulting from high numerical dissipation.

\subsection{Dynamic topography and DieCAST model sur- face circulation}

The Co-operative Marine Science Black Sea program (CoMSBlack; Oguz et al., 1993; Özsoy and Ünluata, 1998) included three basin-wide quasi-synoptic surveys with $1 / 3^{\circ}$ resolution in both the meridional and zonal directions (2-29 September 1991; 4-26 July 1992, and 2-14 April 1993 (western Black Sea only)).

The dynamic topography calculated from these surveys (Fig. 1, right three panels) compares well with the seasonally averaged sea-level elevation produced by DieCAST (Fig. 1, left three panels) for similar times of the year. It is noteworthy that the modeled Rim Current geostrophic sea surface slope $(\sim 16 \mathrm{~cm} / 100 \mathrm{~km})$ and the associated slope of the underlying pycnocline $(\sim 100 \mathrm{~m} / 100 \mathrm{~km}$ on the
$15.8 \sigma_{\mathrm{t}}$-surface) compare well with the dynamic topography gradients $(\sim 12 \mathrm{~cm} / 100 \mathrm{~km} ; \sim 80 \mathrm{~m} /$ $100 \mathrm{~km}$ ) calculated from the observations. This confirms that both the geostrophic transport and nonlinear vertical mixing are well represented in the model, unlike highly diffusive models where they are often underestimated. The width of the Rim Current is $\sim 70 \mathrm{~km}$ (defined as the width of the current where the slope of the pycnocline is $>5 \mathrm{~m} / 100 \mathrm{~km}$ ) and is almost identical in both observations and model. This agreement is fundamental to a realistic simulation of water mass formation, which strongly depends on an accurate representation of stratification, horizontal and vertical circulation.

Another positive result of the present simulations is the intensification of the Rim Current due to reduced stratification and stronger winds during winter and spring (e.g., the modeled slope of the sea surface over the continental slope is significantly larger in April $(\sim 30 \mathrm{~cm} / 100 \mathrm{~km})$ than in July and September $(\sim 14 \mathrm{~cm} / 100 \mathrm{~km}))$. This supports the earlier results of Stanev (1990) and Staneva and Stanev (1998) who demonstrated that the seasonal transport increases by more than $50 \%$ in the winter months.

One important deficiency in earlier efforts that we have overcome is the realistic simulation of both coastal and deep basin eddies (Fig. 2). The modeled Black Sea circulation is dominated by meanders, eddies, filaments and dipole structures with scales comparable to those found during surveys (see Fig. 1 and the papers of Oguz et al., 1993, 1994; Özsoy and Ünluata, 1998). Similar to the observations, the model produces about 12 coastal eddies during an annual run. These form quickly, especially near coastal abutments, and initially have space scales $O(30) \mathrm{km}$ and time scales of a few days, but often merge to form larger eddies having longer time scales. This is slightly lower than Ovchinnikov's (1998) estimate of about 20 eddies. However, his estimate was not derived from synoptic surveys, but rather was based on the number of locations where coastal anticyclones have been observed at some point in time.

The Rossby radius of deformation in the Black Sea is $\sim 20-30 \mathrm{~km}$ and the corresponding diameters of coastal eddies (Fig. 1, upper right panel) are comparable, particularly in the central and the easternmost sections of the basin. 

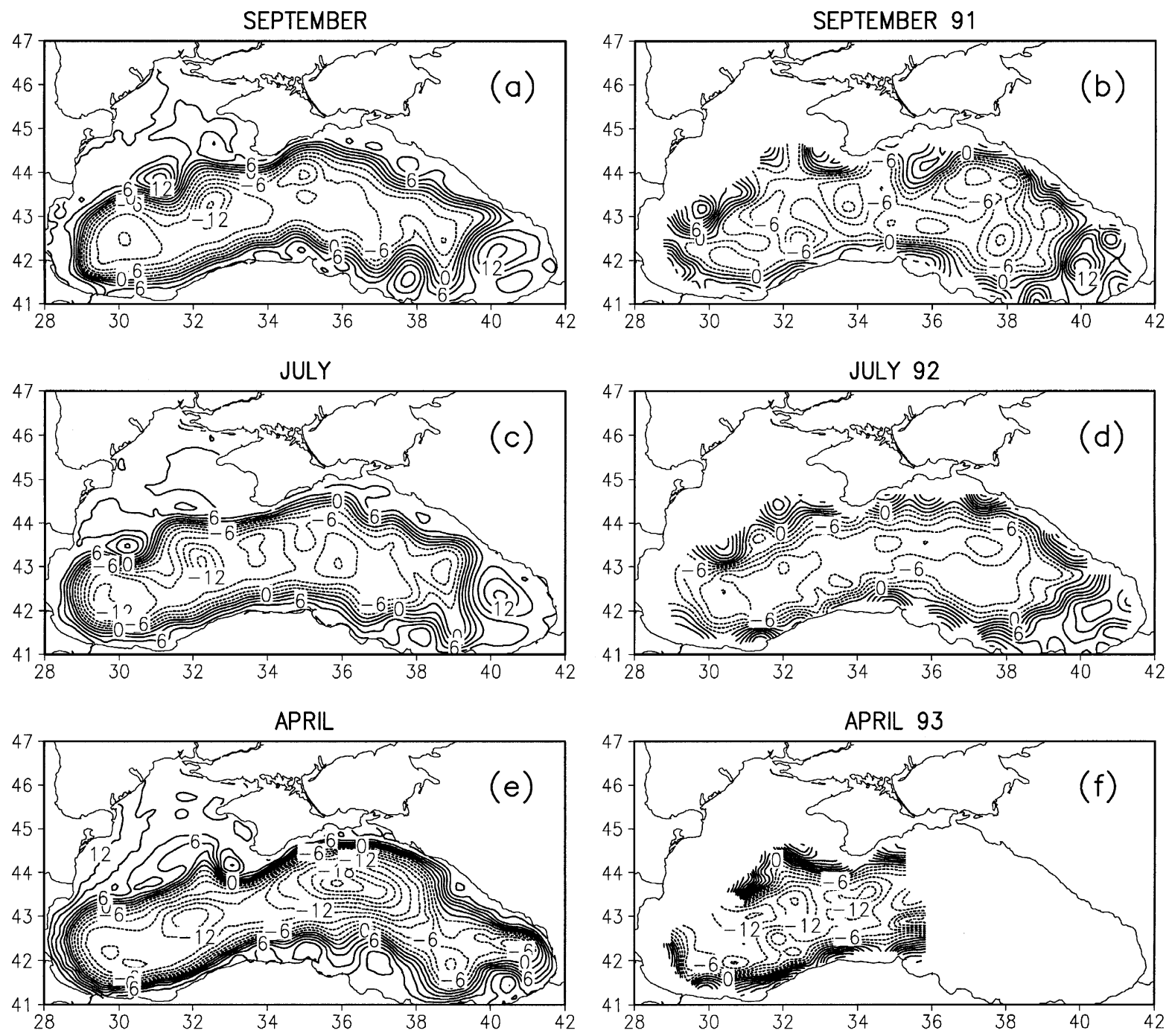

MODEL

\section{SURVEY}

Fig. 1. Sea level (cm) simulated by the model (left panels) and dynamic topography (right panels) calculated from the Black Sea Survey data during (b) HydroBlack'91; (d) COMSBlack'92; (f) COMSBlack'93. The model snapshots correspond to the month when the survey was carried out. The contour interval in all plots is $2 \mathrm{~cm}$.

\subsection{Basin-mode structures and coastal trapped waves}

The western propagation of Rossby waves in the Black Sea was demonstrated in earlier model simulations, forced with both stationary (Rachev and Stanev, 1997) and time varying (Stanev and Staneva, 2000) coastal currents. Similar westward-propagating basin-modes are observed in the present DieCAST simulations. This is illustrated in the time versus longitude Sea Level Anomaly (SLA) plot at $43.5^{\circ} \mathrm{N}$ (Fig. 3a).

The propagation time across the entire basin is $\sim 12$ months in both DieCAST simulations and observational data. The altimeter data from the recent US/French TOPEX/POSEIDON (T/P) mission 


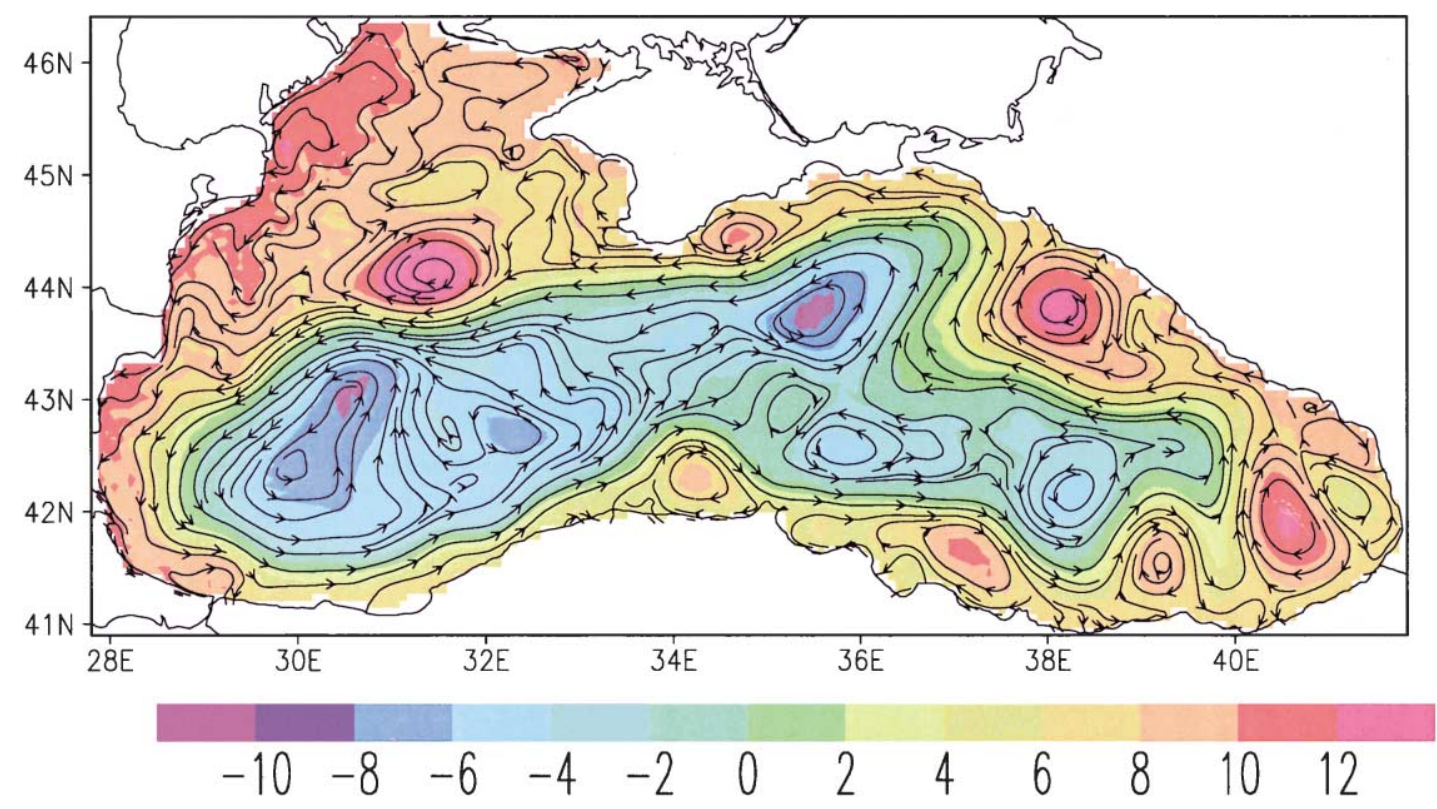

Fig. 2. Snapshot of sea level $(\mathrm{cm})$ simulated by the model and surface streamlines during year 16 . Note the existence of chains of coastal anticyclones including the dominant Batumi and Sebastopol eddies, the eastern and western gyres of the Rim Current and evidence of a small anticyclone imbedded in the Rim Current about $43^{\circ} \mathrm{N}, 35^{\circ} \mathrm{E}$. This plot should be compared with the schematic of the Black Sea surface circulation based on a synthesis of dynamic height derived from hydrographic observations in Oguz et al. (1993).

distributed by AVISO (1996) has a rms error of less than $3 \mathrm{~cm}$, so that typical $10 \mathrm{~cm}$ amplitude Black Sea level variations are adequately resolved. The SLA of the Black Sea is recorded during nine repeat tracks over 1 to 3 days, then mapped once every 10 days using a sub-optimal space/time interpolation method (Le Traon et al., 1998; Stanev et al., 2000). This provides useful coverage for model comparisons.

This is consistent with our previous studies using MOM (Stanev and Staneva, 2000; Stanev and Rachev, 1999) and from the calculations of Latun (1990), based on observations. The period of oscillations is about 1 year, suggesting that these oscillations are induced by annual cycles in atmospheric forcing.

The slopes of time versus longitude contours in SLA (Fig. 3) give a measure of the speed of westward propagating signals. It can be seen that both the magnitudes and the slopes of the SLA in the satellite data correlate well with that of the model simulations. The westward propagation is more pronounced in the interior of the basin, where the topography is relatively flat.
The DieCAST model also produces coastally trapped waves (CTW), which propagate eastward along the southern coast. Such CTWs were first demonstrated by Sur et al. (1994) using sequential CZCS sea-surface colour observations. A time versus longitude diagram at the $1500 \mathrm{~m}$ isobath in the southern Black Sea, spanning west from the Sakarya Canyon to $40^{\circ} \mathrm{E}$ is shown in Fig. 3c. The slope of the contours provides clear evidence of the eastward propagation of the disturbance.

The principal periodicities range from 3 to 6 months. In some locations, the phase speed reaches about $5-8 \mathrm{~cm} \mathrm{~s}^{-1}$, while between $34^{\circ} \mathrm{E}$ and $38^{\circ} \mathrm{E}$ the propagation sometimes stagnates; this might result from the complex topography in this region. The preponderance of small scale features is indicative that processes in the coastal zone are dominated by energetic mesoscale eddies.

To better understand the periodicities in the basin-wide oscillations, we analyzed the spatial structure of the rms amplitude of SLA in both the simulated and $\mathrm{T} / \mathrm{P}$ data (Fig. 4). The zones of highest variability of SLA overlap in the general 

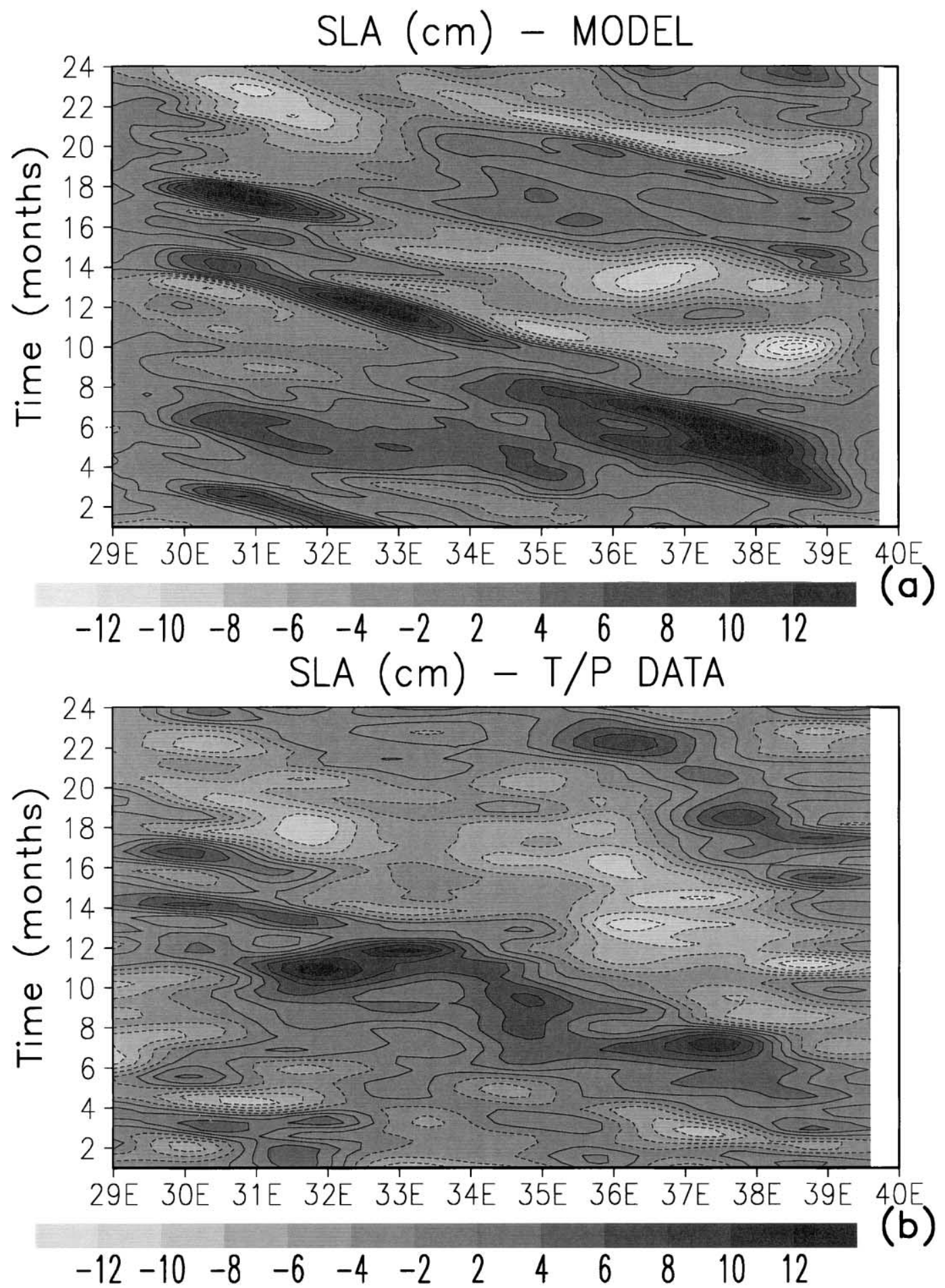

Fig. 3. Time-longitude diagrams. The slope of the contours gives a measure of the speed of wave propagation. (a) Sea level anomaly (SLA) simulated by the DieCAST model at $43.5^{\circ} \mathrm{N}$; (b) SLA from $\mathrm{T} / \mathrm{P}$ data at $43.5^{\circ} \mathrm{N}$; (c) SLA anomaly simulated by the DieCAST model along the southern coast $1500 \mathrm{~m}$ isobath. 


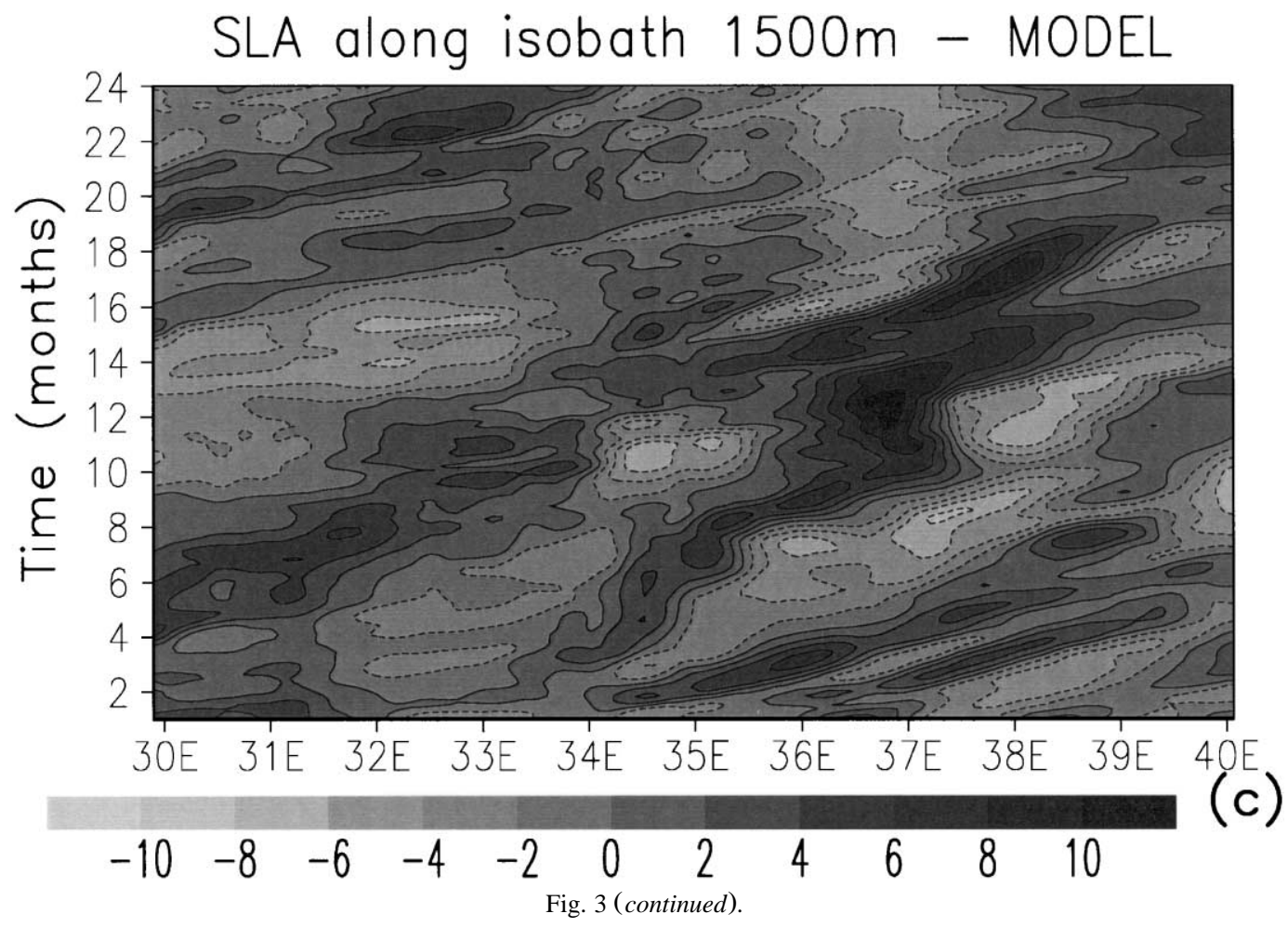

locations of the Batumi, Sakarya and Sevastopol eddies, as well as to the south of Kerch Strait.

Good coherence was also found between the two patterns in some areas of weak oscillations (e.g., just to the west of Batumi eddy and northward of the southern coast at about $33^{\circ} \mathrm{E}$ ). The amplitudes of oscillations are slightly higher in the simulations than in the observations along the southern and northern shelfbreaks. The decrease in model SLA oscillations in the northernmost shelf correlates with the similar decrease in the observations, but as a whole, the northern shelf area in the model does not exhibit substantial variability. Problems can arise when comparing model predictions with $\mathrm{T} / \mathrm{P}$ data due to (i) insufficient resolution between the tracks (only nine tracks cover the Black Sea), introducing interpolation errors when mapping data lines onto a regular grid, and (ii) very short period of observations insufficient to derive stable statistics.

$\mathrm{T} / \mathrm{P}$ time series can also be used to verify the simulations. However, the DieCAST model forcing in its present configuration supports neither inter-annual variability, nor high frequency (periods $<1$ month) forced oscillations. On the other hand, the very low dissipation inherent in DieCAST produces a richness in eddy and meander motions that is absent in models running with higher friction and lower nonlinearity.

The detailed analysis of model results in the remainder of this paper compares the strength of free versus forced motions. We analyze the difference between SLA from the basin-mean elevation in several locations. This difference eliminates the variability associated with the barotropic circulation and gives a clearer picture of the transient variations in circulation.

\subsection{The Batumi eddy}

The most energetic seasonal oscillation in the Black Sea Rim Current is in the eastern Black Sea area, where a strongly seasonal anticyclonic Batumi eddy occurs, which waxes during winter and spring 
RMS of SLA - MODEL DATA

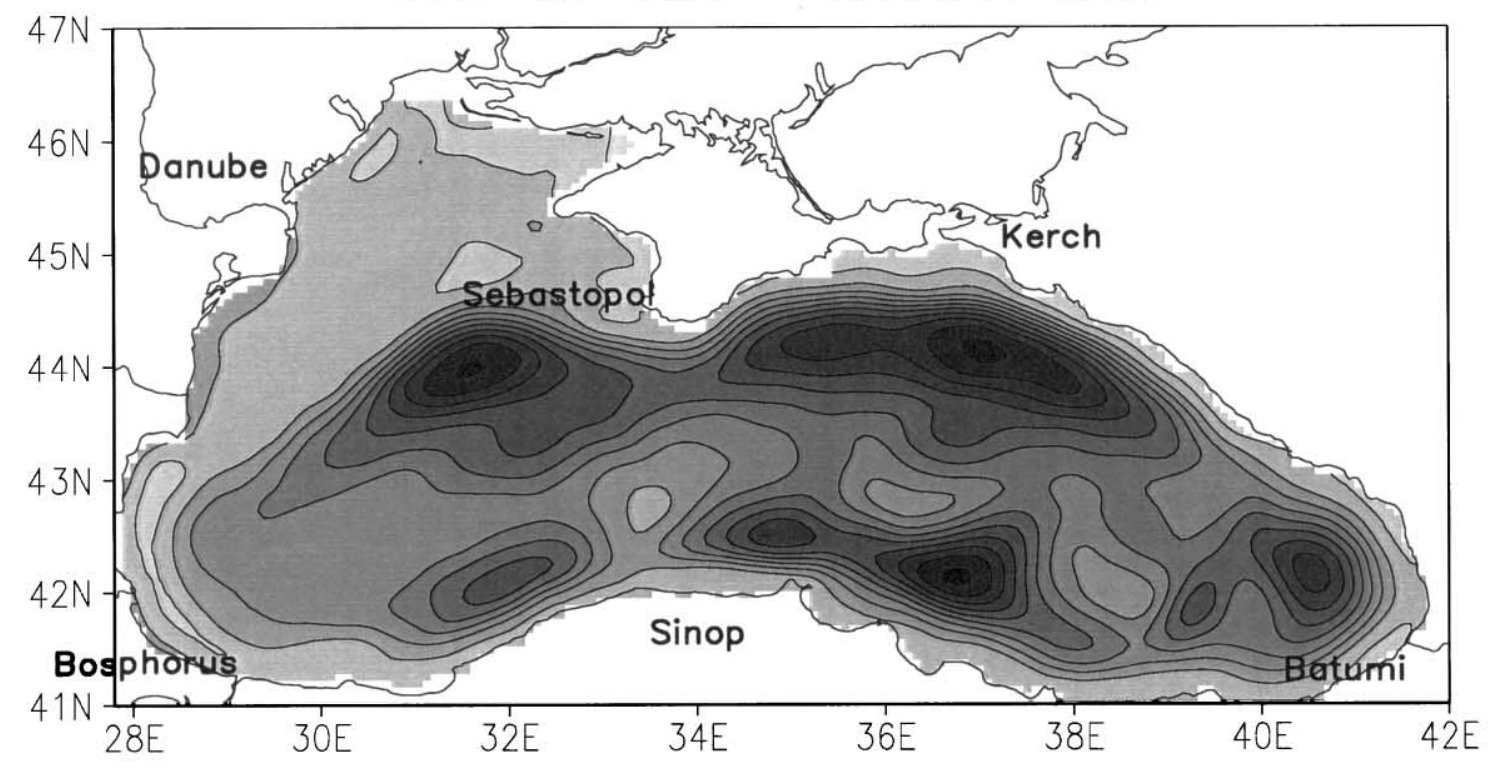

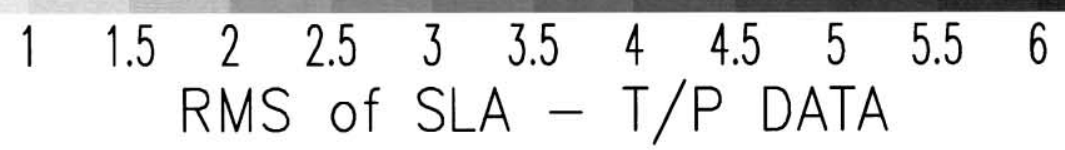

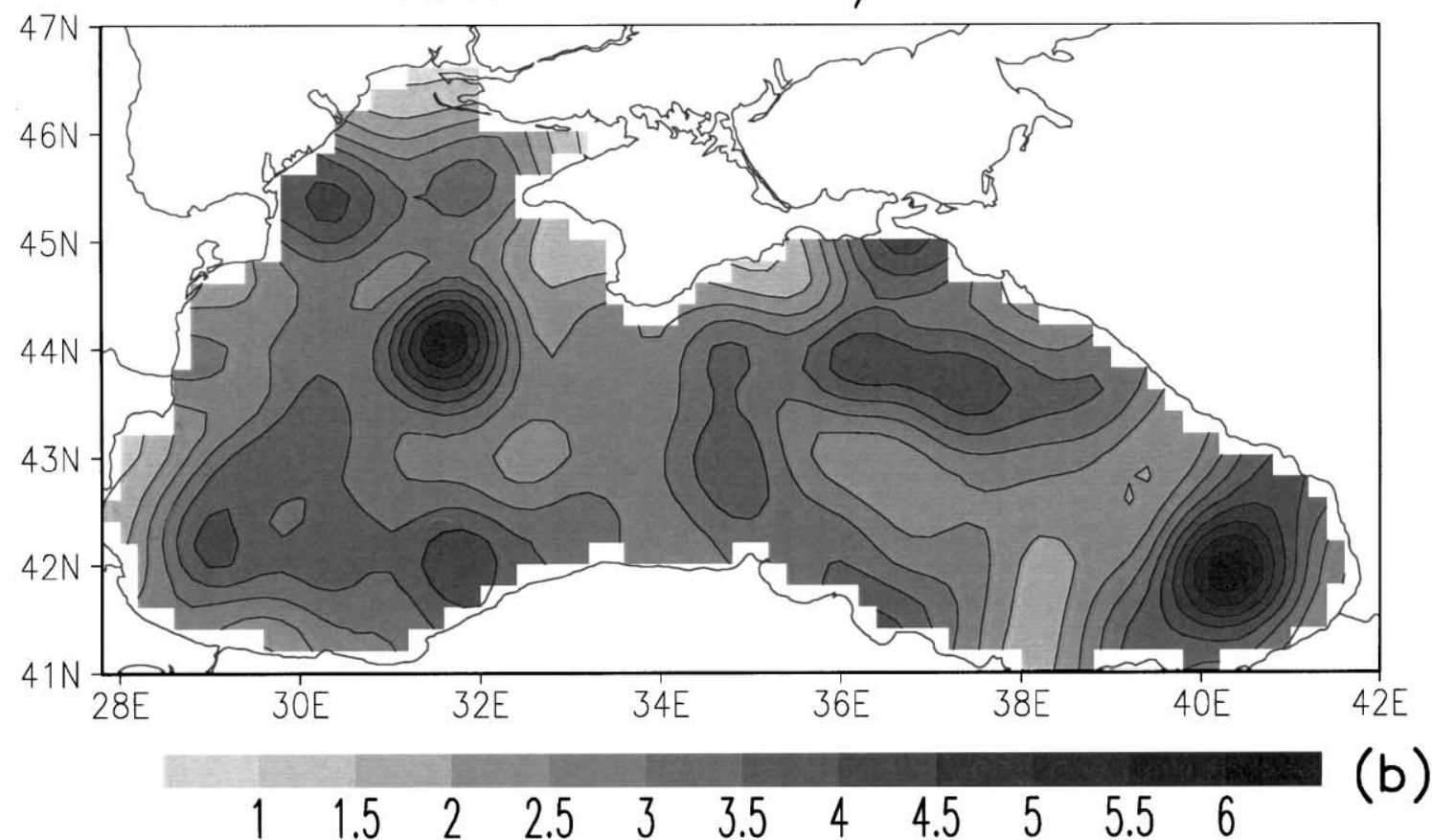

Fig. 4. RMS amplitudes of SLA oscillations (cm). (a) DieCAST simulations; (b) T/P data. 

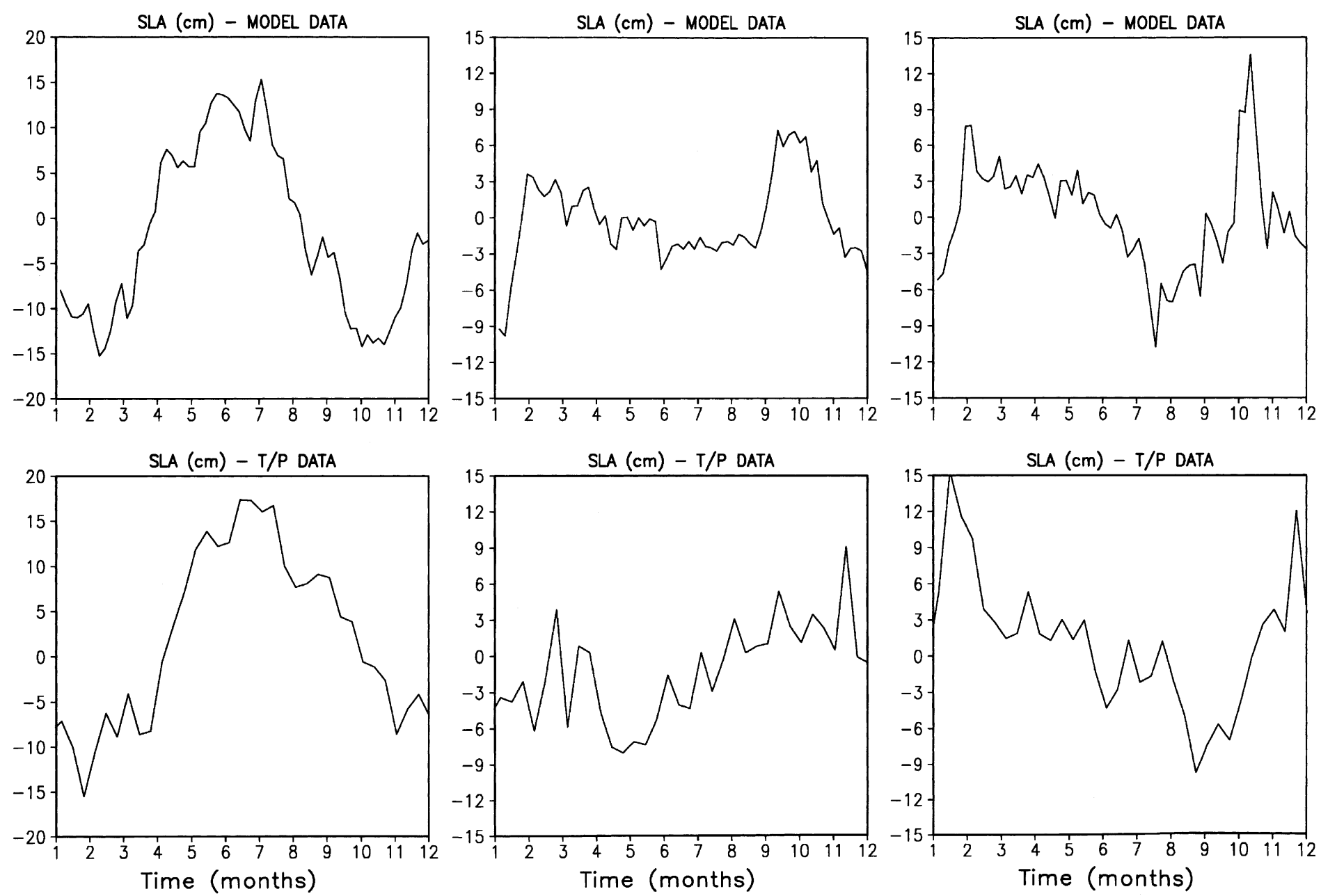

(40 deg.E, 42. deg.N)

(30. deg.E, 43. deg.N)

(32 deg.E, 45. deg.N)

Fig. 5. SLA evolution at different locations of the Black Sea (upper panels correspond to the model data; lower panels to T/P data). The locations are given on the bottom. 
Temperature (Lon, 32; Lat 44.5) DieCAST Model

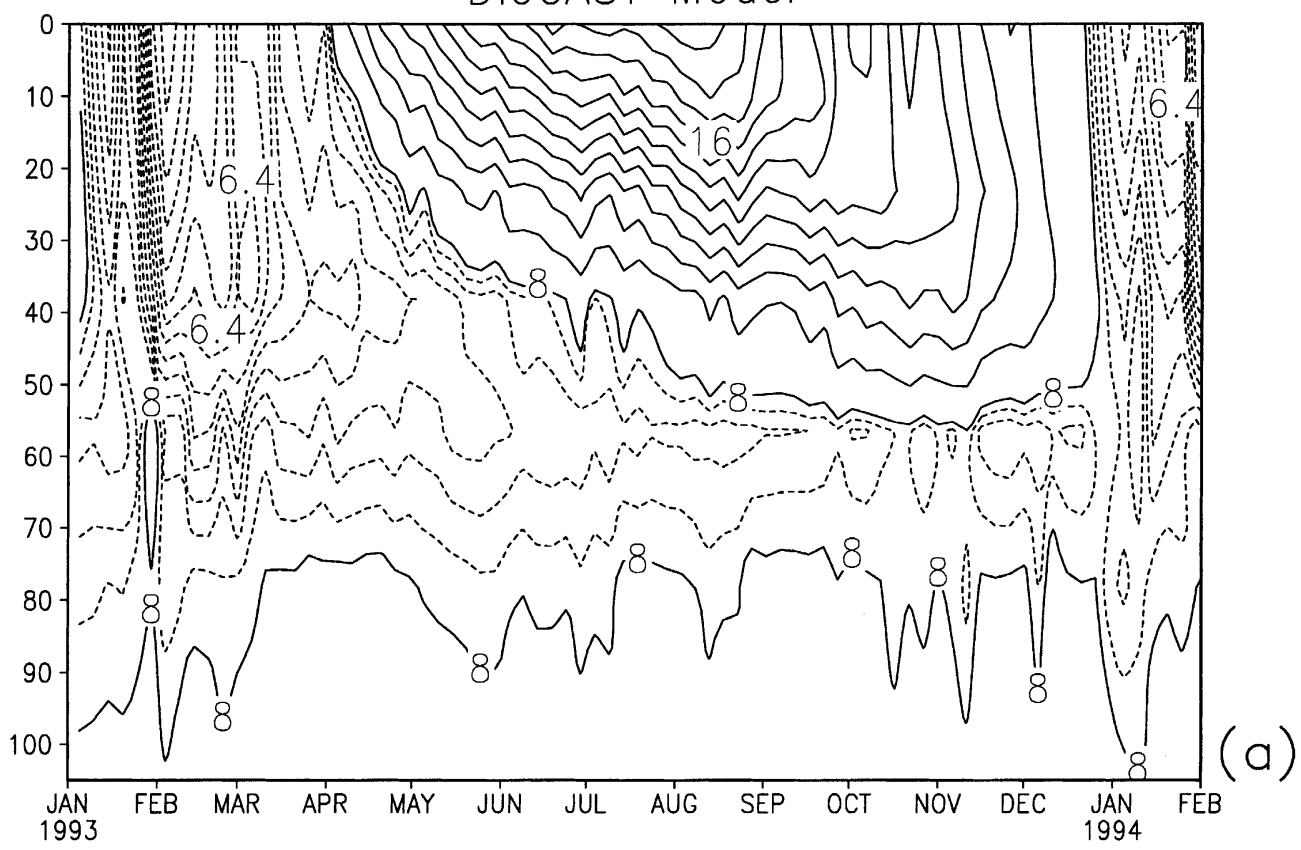

Climatic Data - Belokopytov

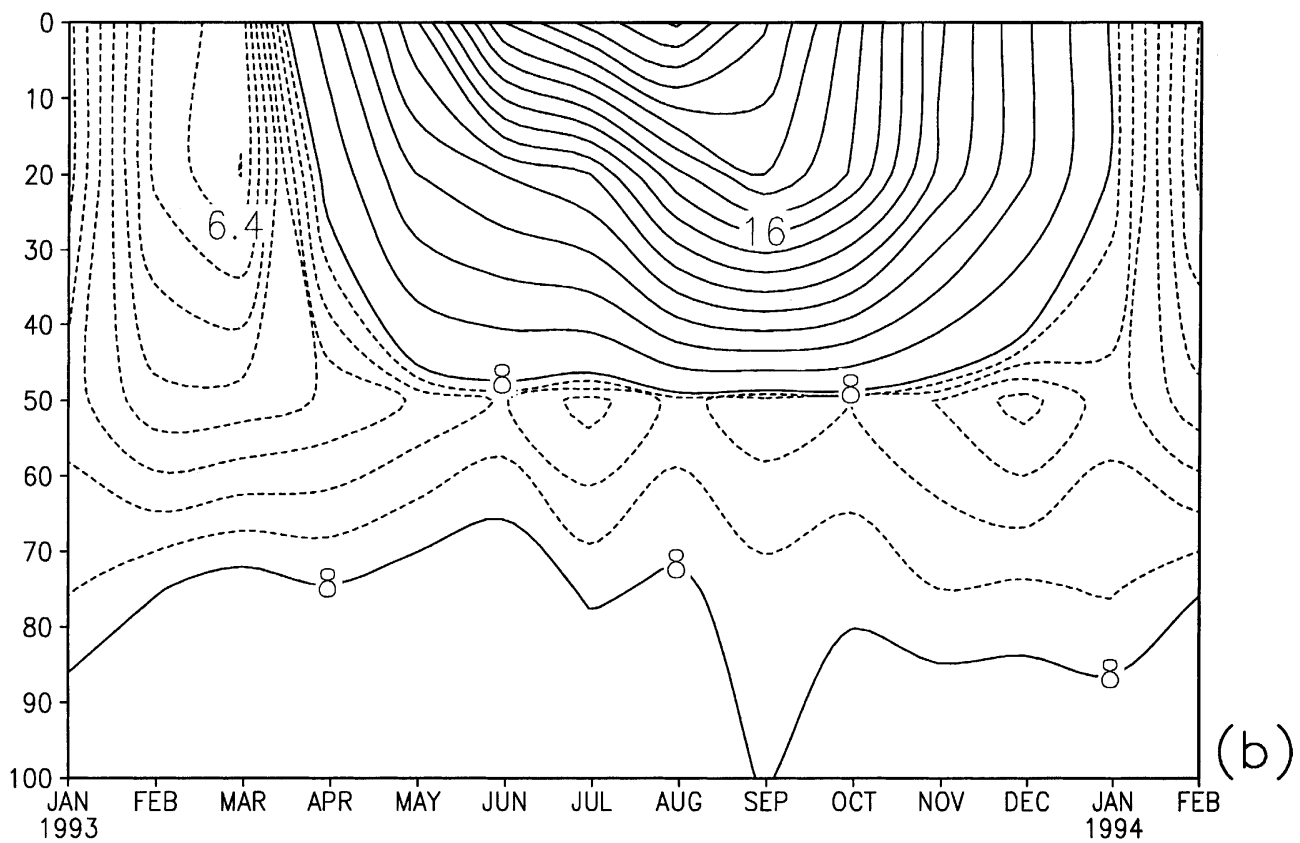

Fig. 6. Time evolution of vertical temperature profiles at $\left(32^{\circ} \mathrm{E}, 44.5^{\circ} \mathrm{N}\right)$. 
and wanes during summer and fall. This is reflected by the large positive SLA, both observed and simulated, during July (Fig. 5). The positive SLA reflects the convergence in levels above the main pycnocline as the buoyant coastal eddies merge in this region. Coastal intermediate waters sink on the small scale of the intense coastal eddies, as described by the vorticity advection term (negative vorticity is advected into the region, thereby pushing water downward as part of geostrophic adjustment) in the quasi-geostrophic omega equation. During the weaker late winter and spring stratification periods, such sinking may occur in combination with baroclinic instability as the sinking waters may be dense due to horizontal advection of dense water into the sinking regions. These interpretations are consistent with those given by Stanev et al. (1997).

The intensification of cyclonic circulation in winter and spring is revealed by the negative anomalies in the area of the Batumi eddy (Fig. 5, left two panels). One important conclusion drawn from Fig. 5 is that the seasonal appearance of the Batumi eddy is quite regular with the largest anticyclonic intensity being exhibited in summer. However, there is also a shorter period cycle revealed in Fig. 5 as a weak secondary maximum occurring in DecemberJanuary. The correspondence between simulations and observations in the area of Batumi eddy is good since the variability is dominated by the seasonal transitions. Thus, our results give indirect support to the conclusions of Stanev and Staneva (2000) that sub-basin eddies are important elements in the transition of the basin-wide Rim Current circulation between its different states.

The sea level at the western basin location $32^{\circ} \mathrm{E}$, $42^{\circ} \mathrm{N}$ shows a quite different behavior (upper and lower right panels in Fig. 5). Here the SLA is positive in winter and negative in summer. This contributes to increasing the slope of the sea surface between the coastal sea and the open ocean, associated with the winter intensification of the Rim Current. As discussed in the more detailed analysis of Stanev et al. $(2000,2001)$, the variability in this region appears mostly at synoptic and inter-annual time scales.

It is particularly important to note the phase differences between the time series representing the western basin location (right panels) and the Batumi eddy (left panels). Both model simulations and $\mathrm{T} / \mathrm{P}$ data demonstrate almost opposite phases. This indicates an increase of cyclonic circulation in winter (positive SLA in coastal station) and an increase of anticyclonic circulation in summer-fall (positive SLA in open sea station). However, as seen in the interior of the western basin (centre two panels), at times the model signal (upper panel) exhibits quite large differences from the observations (lower panel), as well as from the other two regions. Thus, we conclude that the sea level oscillations are highly variable and provide evidence that free basin oscillations are of comparable magnitude to forced oscillations.

\subsection{Convective mixing}

Close agreement of time series of simulated (upper panel) and observed (lower panel) vertical temperature distributions (Fig. 6) encourages us to believe we have adequately modeled the thermodynamics. The presence of winter-time convective mixing is identified by the vertical isolines found in times of lowest SST (January to April). The permanent pycnocline maintained jointly by the inflow of river water and dense Mediterranean Sea water at depth through the Bosphorus strait inhibits deeper winter convection. In such mid-winter periods, the mixed layer depth penetrates down to $\sim 50-60 \mathrm{~m}$ (and the SST correspondingly decreases to $\sim 5-6$ ${ }^{\circ} \mathrm{C}$ ). This is the origin of the CIL. The CIL exists throughout the year, spreading over the entire Black Sea at depths of 50 to $70 \mathrm{~m}$.

The maximum SST of $\sim 24{ }^{\circ} \mathrm{C}$ is observed during August. This ambient stratification is key to understanding the formation of coastal eddies. There are two typical states: the first in winter characterized by very weak stratification and the second in summer when vertical stability increases and tends to change the potential vorticity of the upper layers of the water column.

\section{Formation and dynamics of coastal eddies}

Coastal eddies in the Black Sea are typically elongated, anticyclonic gyres wedged between the main cyclonic Rim Current over the shelfbreak and 
the coast. The coastal anticyclones are formed principally by fluid elements shedding from elongated recirculating wakes structures formed behind coastal headlands (see Dietrich et al., 1996 for a discussion of the analogous dynamics of eddy wakes behind oceanic islands). They are often very energetic; we now discuss characteristic behaviors associated with the genesis of the Batumi and Sevastopol eddies (Figs. 7 and 8). Since vorticity dynamics play an important role in the evolution of coastal anticyclones, we plot both surface currents and their relative vorticity (coloured contours). The bottom topography affects the speed of coastal eddies relative to advection by the mean flow associated with the Rim Current via the topographic beta effect.

\subsection{The Batumi eddy}

One interesting area is the easternmost (Batumi) region where the widened shelfbreak apparently slows down topographic waves, propagating counterclockwise around the basin perimeter. This deceleration results in the "catching up" and merging of sequential eddies into a more circular shape (Fig. 7). During late winter and early spring, coastal eddies formed along the south coast merge into the dominant Batumi eddy, which itself spawns offshore filaments that mix with the coastal waters. Vorticity elements merge very rapidly into one another during the formation of the Batumi eddy; even snapshots at 5-day intervals do not sufficiently resolve the merging process.

The Batumi eddy then gets trapped for a time in the far eastern corner, sometimes exhibiting small, yet intense, frontal cyclones that form and advect around the perimeter of the Batumi eddy. Such effects have also been modeled in the Gulf of Mexico (see Dietrich et al., 1997, for a discussion of cyclogenesis produced by shear in the squeezed region between the major anticyclone and the coast) and the East Australian Current (Bowman et al., 2001). Various mechanisms for the trapping of the Batumi eddy are being investigated and will form the basis of a further publication.

\subsection{The Sevastopol eddy}

The resulting fine-scale anticyclonic eddies and vortex filaments that peel off the Crimean headlands merge into a particularly strong Crimean wake recirculation eddy during this period of weak stratification (Fig. 8; note that the relative vorticity contoured in Figs. 7 and 8 is normalized by the basin-mean Coriolis parameter $\left(f=10^{-4} \mathrm{~s}^{-1}\right)$ and multiplied by 10). Mesoscale processes near the Crimean Peninsula and their interaction with the shelf can substantially affect the regional mixing of chemical contaminants, biological organisms and water mass formation. The anticyclonic eddy formed to the west of the peninsula entrains water originating in the basin interior (with cyclonic rotation). This interior water wraps itself around the anticyclonic coastal water as well as penetrating its centre (Fig. 8). The inverse process of leakage of coastal waters (possessing anticyclonic vorticity) into the basin interior is periodically observed south of Kerch Strait and is supported by survey and altimeter data (see Sokolova et al., 2001, this issue).

Soon after its formation (days 385-395), the Sevastopol eddy (Fig. 8) propagates westward (days 395-405), while at the same time increasing its anticyclonic rotation. After reaching its maximum intensity, it appears to stagnate (days 405-420; Fig. 8) and its diameter increases substantially. It is thought that the arc-like topography in this region entraps the coastal anticyclone until its energy is dissipated. Further down the current, the water wedged between the jet current and the continental slope flows westwards giving rise to a new anticyclonic eddy (day 450 , at $44^{\circ} \mathrm{N}, 31.5^{\circ} \mathrm{E}$ not shown here). The eddy exits the region at $43.75^{\circ} \mathrm{N}, 31^{\circ} \mathrm{E}$ by day 510 .

\subsection{Selective dissipation of anticyclonic vorticity}

The phenomenon of selective dissipation of anticyclonic vorticity is important in shallow-sea eddy dynamics. Upper level water columns are strongly constrained by the pycnocline, so most of the exchange with coastal waters involves flow trapped above the pycnocline. Thus, for the main exchanges across the Rim Current, the effective depth is the pycnocline in deep water. When water moves shoreward across depth contours it advects the lower potential vorticity $(\psi+f) / D \sim f / D$ of the deep water with it. Thus, it develops negative relative vorticity $\psi$ due to water column squashing as it moves shoreward into shallow areas. Over time, this nega- 

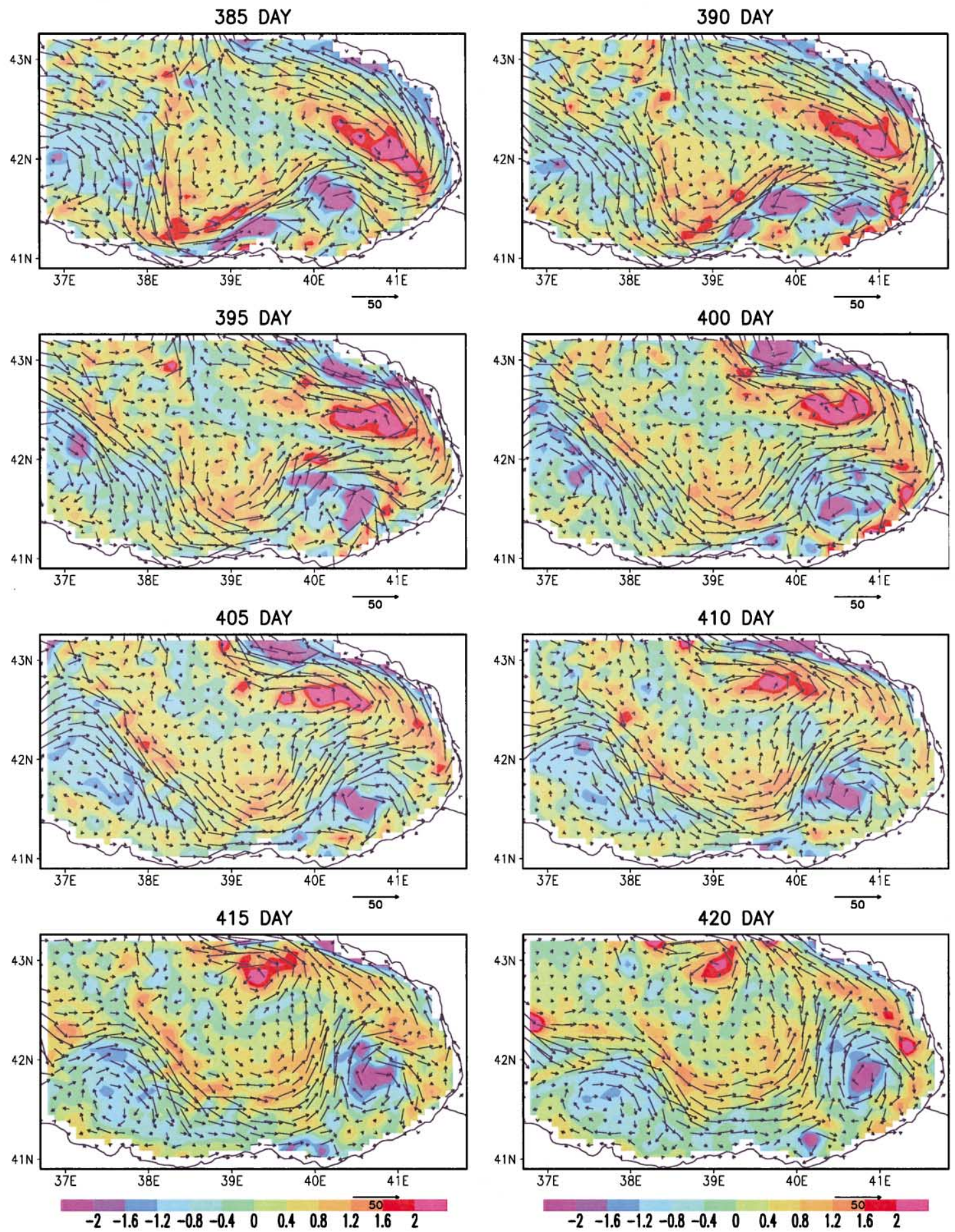

Fig. 7. Time sequence (at 5-day intervals) of currents and relative vorticity in the area of the Batumi eddy (relative vorticity is normalized by the Coriolis parameter and multiplied by 10$)$. 

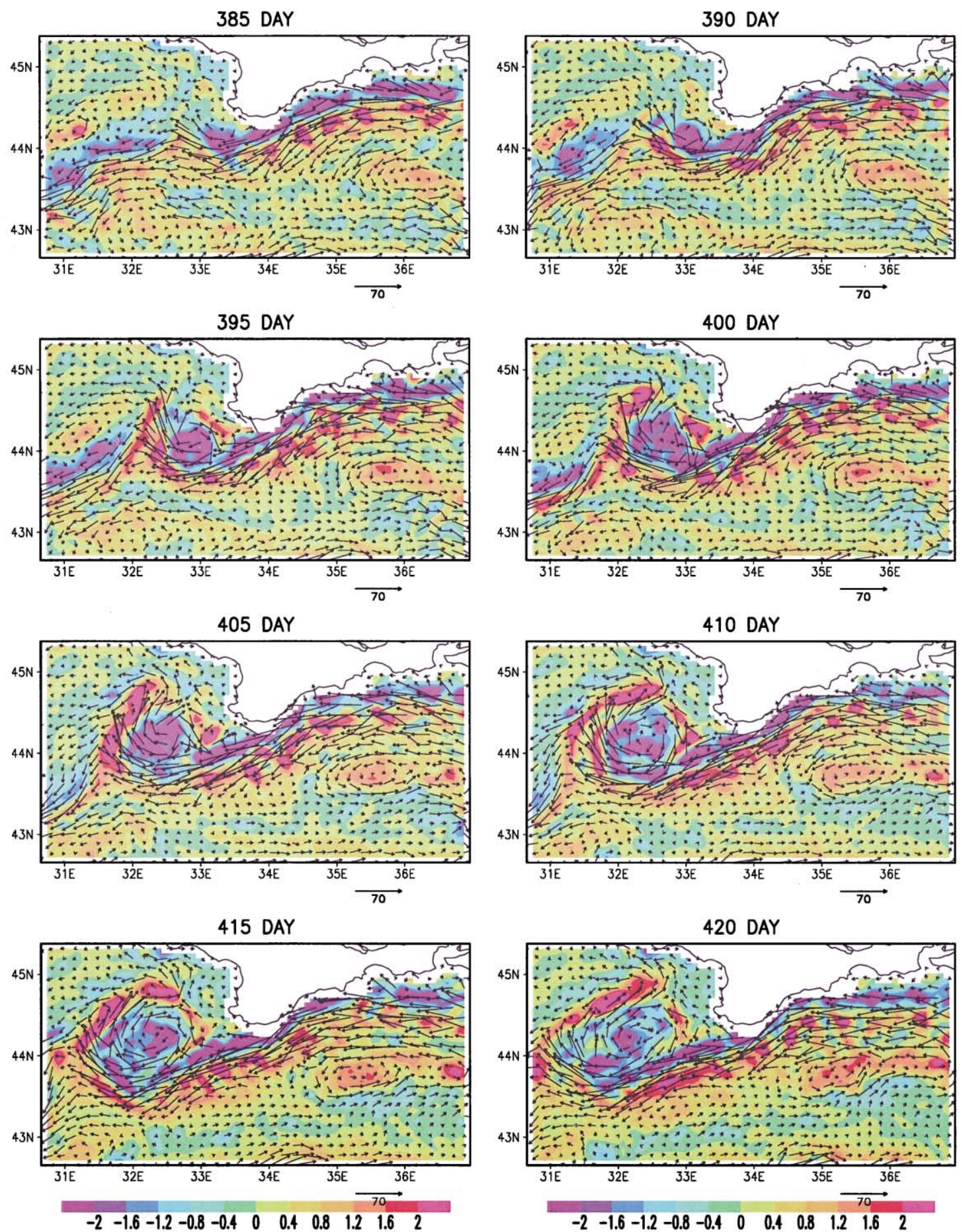

Fig. 8. Time sequence (at 5-day interval) of currents and relative vorticity in the area of the Sevastopol eddy (relative vorticity is normalized by the Coriolis parameter and multiplied by 10$)$. 
tive relative vorticity is dissipated by friction in the coastal regions, thereby increasing the potential vorticity (see Dietrich and Mehra (1998) for further details). To conserve volume, an equal volume of water must leave the coastal region elsewhere. The compensating water, having resided in the coastal band for some time, will generally have larger potential vorticity than the shoreward moving water. Thus, there is a positive correlation between the magnitude of potential vorticity and the offshore velocity component, integrated around the basin perimeter.

This means the deep water will naturally tend to develop positive relative vorticity $\psi$ as a result of dissipation occurring selectively in the shallow coastal regions. The cross-Rim Current vorticity transport apparently converges rapidly on the interior side of the current, reinforcing its jet-like structure. This Rim Current jet formation mechanism is most effective during winter and spring, when the water columns in the coastal regions and above the pycnocline are less stratified, reducing the buoyancy constraint on vertical motions and thus leading to larger vortex squashing as material elements move across greater depth ranges (see Section 3). This mechanism is further enhanced by the deepening of the pycnocline as the winter convection penetrates downward.

\subsection{Seasonal effects}

Wind curl effects may be secondary in enhancing relative vorticity for a basin with the size of the Black Sea (Rachev and Stanev, 1997; Staneva and Stanev, 1998), but there are still substantial thermohaline effects on the coastal eddies (Ovchinnikov, 1998); the seasonal change in Black Sea thermal stratification between its permanent halocline and the surface is one of them.

Coastal headland wake eddies tend to form during winter and spring, when the water column stratification is relatively weak. During summer and autumn, anticyclonic wakes, especially smaller scale coastal wakes, are suppressed by the strong stratification. According to the omega equation of quasi-geostrophic (slowly varying) dynamics, anticyclonic, upper-level advection tends to force sinking motion. This would transport buoyant surface water downward, thus converting eddy kinetic energy into poten- tial energy. This mechanism works against the "the normal" transfer of energy from available potential energy into kinetic energy, thereby tending to eliminate such eddies.

During winter, surface cooling decreases vertical stratification, but has less effect on horizontal buoyancy gradients, which are controlled mainly by the entrainment of river water into the coastal currents. The weakly stratified winter environment thus is more favorable for the generation of anticyclonic headland wake eddies, such as the Sevastopol eddy to the west of the Crimean Peninsula (Fig. 8).

In late February, the basin-mean surface temperature drops to its annual minimum of $\sim 8{ }^{\circ} \mathrm{C}$ and the upper water column stratification is weakest. The shelf-break jet is generally strongest near the coast (Figs. 7 and 8). The jet is most intense southeast of the Crimean Peninsula (Fig. 8), due to the convergence of the shelf-break contours along the path of the jet. At one location (southeast and adjacent to the Crimean peninsula), the anticyclonic relative vorticity of the jet is $\sim-8.6$ day $^{-1}\left(\sim-1.0 \times 10^{-4}\right.$ $\left.\mathrm{s}^{-1}\right)$, giving an absolute vorticity of near zero $(f=$ $1.1 \times 10^{-4} \mathrm{~s}^{-1}$ at $\left.44^{\circ} \mathrm{N}\right)$. This is inertially neutral and thus allows local buoyancy to act free from the normally strong rotational constraint. In addition, the local baroclinicity and, hence, buoyancy forces are also locally strong.

\subsection{Interannual variability}

The Batumi eddy forms quasi-periodically (Sokolova et al., 2001, this issue). However, its appearance differs from year to year, exhibiting a pronounced inter-annual signal. Unlike the real Black Sea where sequential manifestations of the Batumi eddy are likely due to fluctuations in inter-annual atmospheric forcing, the DieCAST simulation, with its annually repeating forcing, demonstrates that small perturbations trigger off mesoscale motions which differ in detail from year to year.

Although careful sensitivity studies are needed to determine the exact causes of these variations, it appears that during some years, the Batumi eddy tends to form further offshore as a result of an early northward deflection of the Rim Current upstream (Fig. 7). The result is that the anticyclonic headland 
wake features are advected offshore by the northward deflected current, further enhancing its early deflection, thus forming the Batumi eddy slightly offshore and west of its usual southeastern Black Sea coast-hugging location.

The dominating vorticity balance in the Black Sea is maintained by the interplay between the interior (cyclonic) and coastal (anticyclonic) circulation (Stanev and Staneva, 2000). As discussed in Section 3 , decreases in intensity of the cyclonic interior circulation are accompanied by corresponding increases in the intensity of the anticyclonic circulation in the Batumi region. Under such conditions, the Rim Current is displaced westwards and the local anticyclonic circulation starts to dominate.

However, the second mode of circulation (viz., coastal currents flowing with the coast on their left; Fig. 7) reduces the influx of water parcels with anticyclonic rotation. Dissipation also tends to reduce the intensity of the Batumi eddy, which gives rise to the inverse process (intrusion of cyclonic meanders from the Rim Current eastwards), leading to eastward erosion of the Batumi eddy.

\section{Conclusions}

In this paper, results have been discussed from both models and observations to illustrate the importance of mesoscale eddies and meanders on the exchange of water between coastal and open-sea waters and on the ventilation of the pycnocline. The analysis has revealed some fundamental features of the Black Sea circulation: the quasi-permanent cyclonic Rim Current located over the continental slope and the existence of a considerable number of anticyclonic meanders and eddies lying between the Rim Current and the coast. These eddies play a fundamental role in coastal and open-sea exchange processes; recent Topex-Poseiden $(\mathrm{T} / \mathrm{P})$ altimeter data strongly supports these hypotheses.

As shown in other observations and modeling studies (e.g., Ovchinnikov and Popov, 1987; Staneva and Stanev, 1997), mixing in the interior Black Sea contributes substantially to the formation of the ventilation of the pycnocline and the cold intermediate water (CIW) formation. Mesoscale eddies, enhanced by basin-wide oscillations, could additionally modify the ventilation of intermediate layers.

In the last section of this paper, we discussed mechanisms controlling the variability in dynamically important areas (viz., coastal anticyclones and the Batumi and Sevastopol eddies). A fundamental characteristic of the Black Sea, which is intimately related to the exchange of coastal and open-sea waters, is the strong vertical stratification. It effectively blocks vertical mixing, in which case breaking internal waves at the permanent halocline interface, interacting with the shelf and continental slope might be another important mixing mechanism. Such mixing in the halocline might affect the thickness of the Black Sea cold intermediate water layer. This would partially explain the importance of strong signals generated in the coastal areas to lateral mixing in the interior of the Black Sea.

The DieCAST ocean model, adapted to the Black Sea conditions including the conservation of salt and water in a sea having a strong halocline, has simulated the intense cyclonic Rim Current gyre system and the important fine-scale coastal anticyclonic eddies. Many model circulation features are validated by observations. Simulating the marginally resolved intense narrow Rim Current jet current and coastal anticyclones necessitated using unfiltered bathymetry, very low dissipation, and fourth-order-accurate, reduced dispersion numerics.

The results indicate that the strong seasonal stratification cycle may have an important influence on coastal anticyclogenesis through nonlinear dynamics. Such dynamics include interactions of the coastal eddies with the Rim Current itself, with other eddies and with the coastal abutments which produced them in the first place. The work in progress is investigating in further detail the mechanisms of baroclinic instability, coastal abutment wake recirculations, shedding and selective dissipation of anticyclonic vorticity in the coastal region.

\section{Acknowledgements}

The authors thank P.Y. Letraon for providing altimeter data. Data from the CoMSBlack surveys have been prepared in the context of the NATO 
Black Sea project. We are very thankful to B. Anderson for his useful comments. This work was supported by the CEC Contract IC15-CT96 0113.

\section{Appendix A. DieCAST model equations}

Conservation of $x$ momentum:

$$
\begin{aligned}
\frac{\partial u}{\partial t}= & -\underset{\sim}{\nabla} \cdot \underset{\sim}{\underset{\sim}{\nabla}+f v}-\frac{1}{\rho_{0}} \frac{\partial p}{\partial x} \\
& +A_{\mathrm{h}} \nabla^{2} u+\frac{\partial}{\partial z}\left(A_{\mathrm{v}} \frac{\partial u}{\partial z}\right)
\end{aligned}
$$

Conservation of $y$ momentum:

$$
\begin{aligned}
\frac{\partial v}{\partial t}= & -\underset{\sim}{\nabla} \cdot \underset{\sim}{\nabla}-f u-\frac{1}{\rho 0} \frac{\partial p}{\partial y} \\
& +A_{\mathrm{h}} \nabla^{2} v+\frac{\partial}{\partial z}\left(A_{\mathrm{v}} \frac{\partial v}{\partial z}\right)
\end{aligned}
$$

Conservation of salt (or potential temperature):

$$
\frac{\partial S}{\partial t}=-\underset{\sim}{\nabla} \cdot \underset{\sim}{V}+K_{\mathrm{h}} \nabla^{2} S+\frac{\partial}{\partial z}\left(K_{\mathrm{v}} \frac{\partial S}{\partial z}\right)
$$

Conservation of mass:

$\underset{\sim}{\nabla} \cdot \underset{\sim}{V}=0$

Hydrostatic equation:

$$
\frac{\partial p}{\partial z}=-(\rho-\bar{\rho}) g
$$

Equation of state:

$\rho=\rho(S, \theta)$

where $u=x$ component of horizontal velocity vector $\underset{\boldsymbol{V}}{\boldsymbol{V}} \boldsymbol{v}=y$ component of horizontal velocity vector $\underset{\sim}{\boldsymbol{V}}$; $\tilde{f}=$ Coriolis parameter; $\rho_{0}=$ mean density; $\bar{\rho}=$ horizontally averaged density at depth $z ; p=$ pressure; $A_{\mathrm{h}}=$ horizontal eddy viscosity; $A_{\mathrm{v}}=$ vertical eddy viscosity; $S=$ salinity; $K_{\mathrm{h}}=$ horizontal eddy diffusivity; $K_{\mathrm{v}}=$ vertical eddy diffusivity; $\theta=$ potential temperature.

\section{Appendix B. Parameterization of vertical mixing}

Vertical viscosity and diffusivity $A_{\mathrm{v}}$ and $K_{\mathrm{v}}$ are given by the formulae:

$$
\begin{aligned}
& A_{\mathrm{v}}=0.02+\min \left(10,100 R^{2}\right)+R|\mathbf{W}| \mathrm{d} z / R e \\
& K_{\mathrm{v}}=0.02+R \min \left(10,100 R^{2}\right)+R|\mathbf{W}| \mathrm{d} z / R e, \\
& R=1 /(1+5 R i)
\end{aligned}
$$

(cgs units are assumed). $|\mathbf{W}|$ is the vertical velocity magnitude, $\mathrm{d} z$ is the vertical grid interval, $R i$ is the gradient Richardson number, and $R e$ is the specified vertical cell Reynolds number. This is simply a non-dimensional ratio of advection to so-called "turbulent diffusion" for variations having the scale of order one model grid interval.

The first term in Eqs. (1) and (2) represent laminar diffusivity. The second one is a standard Pacanowski and Philander (1981) mixing parameterization. The third is a generally small mixed physi$\mathrm{cal} /$ numerical term, assigned a value of 10 , which avoids cell Reynolds number overshoots by vertical advection (Roache, 1976), such as produced by internal waves. It allows extremely small vertical mixing necessary to maintain the cold intermediate layer (CIL) throughout the model year. As discussed in the text, the CIL is replenished every winter with cold surface water due to convection, occupies the depth interval 50-150 m; its local topography depends on the vertical circulation. The physical processes represented by terms two and three are the vertical Reynolds stress terms representing the nonlinear interaction of subgrid-scale flow components with resolved scales. These diffusion terms are conventional ad hoc representations of the subgrid-scale effects which have limited basis outside of boundary layers.

To simulate the nonlinearly increased near-surface mixing caused by synoptic winds (because we used less energetic monthly mean wind forcing), the first terms on the right-hand side of Eqs. (1) and (2) are 
enhanced seasonally. In the top three model layers, values used were: 20,10 and $5 \mathrm{~cm}^{2} \mathrm{~s}^{-1}$ during winter; and 1.0, 0.5 and $0.25 \mathrm{~cm}^{2} \mathrm{~s}^{-1}$ during summer, respectively.

\section{References}

Altman, E.N., Kumish, N.I., 1986. Interannual and seasonal variability of the Black Sea fresh water balance, Trudy Gos. Oceanogr. Inst. 145, 3-15 (in Russian).

Aubrey, D.G., Oguz, T., Demirov, E., Ivanov, V., McSherry, T., Diaconu, V., Nikolaenko E., 1993. Hydroblack'91 CTD Intercalibration Workshop. UNESCO, Intergovernmental Oceanographic Commission, Workshop report No. 91, 56 pp. +6 Annexes.

AVISO, 1996. User Handbook: Merged TOPEX/POSEIDON products. AVI-NT-02-101-CN, Edition 3.0.

Beckers, J.-M., 1991. Application of a 3D model to the Western Mediterranean. J. Mar. Sys. 1, 315-332.

Beckers, J.-M., Gregoire, M.L., Nihoul, J., Stanev, E., Staneva, J., Lancelot, C., 2001. Hydrodynamical processes governing exchanges between the Danube the north-western continental shelf and the Black Sea basin simulated by 3D and box models. Estuarine Coast Shelf Sci., Supplementary issue (in press).

Blatov, A.S., Bulgakov, N.P., Ivanov, V.A., Kosarev, A.N., Tujilkin, V.S., 1984. Variability of Hydrophysical Fields in the Black Sea. Gidrometeoizdat, Leningrad, 240 pp. (In Russian).

Blumberg, A.F., Mellor, L., 1987. A description of three-dimensional coastal ocean model. In: Heaps, N. (Ed.), Three Dimensional Shelf Models. Coastal Estuarine Sci., vol. V. Am. Geophys. Union, Washington, DC, pp. 1-16.

Bowman, M.J., Dietrich, D.E., Sanderson, B.G., 2001. Non linear interactions of mesoscale eddies in the East Australian Current. Proceedings of the Konstantin Fedorov Memorial Symposium, St Petersburg, Russia, 18-22 May, 1998. International Oceanographic Commission, UNESCO.

Demishev, S.G., 1996. Numerical energy balanced model of the ocean baroclinic currents. Thesis for obtaining scientific degree Doctor in Physics and Mathematics, Sevastopol, 259 pp. (In Russian).

Dietrich, D.E., 1981. A program of elliptic solver development and implementation in semi-Implicit numerical ocean circulation models. JAYCOR Final Report \#J510-81-053/2192. La Jolla, CA.

Dietrich, D.E., 1997. Application of a modified "a" grid ocean model having reduced numerical dispersion to the gulf of Mexico circulation. Dyn. Atmos. Oceans 27, 201-217.

Dietrich, D.E., Mehra, A., 1998. Sensitivity studies in the Santa Barbara channel using the DieCAST Ocean model. Proceedings of the Santa Barbara Channel Quality Review Board Meeting, San Diego, February.

Dietrich, D.E., McDonald, B.E., Warn-Varnas, A., 1975. Opti- mized block implicit relaxation. J. Comp. Physiol. 18, 421439.

Dietrich, D.E., Marietta, M.G., Roache, P.J., 1987. An ocean modeling system with turbulent boundary layers and topography: Part 1. Numerical description. Int. J. Numer. Methods Fluids 7, 833-855.

Dietrich, D.E., Bowman, M.J., Lin, C.A., Mestas-Nunez, A., 1996. Numerical studies of small island wakes in the ocean. Geophys. Astrophys. Fluid Dyn. 83, 195-231.

Dietrich, D.E., Lin, C.A., Mestas-Nunez, A., Ko, D.-S., 1997. A high resolution numerical study of gulf of Mexico fronts and eddies. Meteorol. Atmos. Phys. 64, 187-201.

Gent, P., McWilliams, J., 1990. Isopycnal mixing in ocean circulation models. J. Phys. Oceanogr. 20, 150-155.

Korotaev, G.K., Saenko, V.A., Koblinsky, C.J., Knysh, V.V., 1998. Study of the Black Sea circulation using Topex-Poseidon altimetry. Earth Res. Space 3, 3-17.

Latun, V.S., 1990. Anticyclonic eddies in the Black Sea in summer of 1984. Sov. J. Phys. Oceanogr. 1 (4), 279-286.

Le Traon, P.Y., Nadal, F., Ducet, N., 1998. An improved mapping method of multi-satellite altimeter data. J. Atmos. Ocean Technol. 25, 522-534.

Nihoul, J.C.J., Deleersnijder, E., Djenidi, S., 1989. Modeling the general circulation of shelf seas by $3 \mathrm{D} k-\in$ models. Earth Sci. Rev. 26, 163-189.

NOAA, 1988. Data Announcement 88-MGG-02, Digital Relief of the Surface of the Earth. NOAA, National Geophysical Data Center, Boulder, CO.

Oguz, T., Latun, V.S., Latif, M.A., Vladimirov, V.V., Sur, H.I., Markov, A.A., Özsoy, E., Kotovshchikov, B.B., Eremeev, V.V., Ünluata, Ü., 1993. Circulation in the surface and intermediate layers in the Black Sea. Deep-Sea Res. 1 (40), 1597-1612.

Oguz, T., Aubrey, D.G., Latun, V.S., Demirov, E., Koveshnikov, L., Sur, H.I., Diaconu, V., Besiktepe, S., Duman, M., Limeburner, R., Eremeev, V., 1994. Mesoscale circulation and thermohaline structure of the Black Sea observed during Hydroblack 1991. Deep-Sea Res. 1 (41), 603-628.

Oguz, T., Malanotte-Rizzoli, P., Aubrey, D., 1995. Wind and thermohaline circulation of the Black Sea driven by yearly mean climatological forcing. J. Geophys. Res. 100 (C4), 6846-6865.

Ovchinnikov, I.M., 1998. Interaction between surface and deep waters in the process of transverse circulation of the Black Sea, ventilation of the Black Sea's anoxic waters. Workshop Rep. Serie no. 1/05/98, Liege, Belgium, pp. 135-161.

Ovchinnikov, I.M., Popov, Yu.I., 1987. Evolution of the cold intermediate layer in the Black Sea. Oceanology 27, 555-560.

Özsoy, E., Ünluata, Ü., 1998. The Black Sea. In: Robinson, A., Brink, K. (Eds.), 1998. The Sea, vol. 11. Wiley, pp. 889-914.

Pacanowski, R.C., Philander, S.G.H., 1981. Parameterization of vertical mixing in numerical models of tropical oceans. J. Phys. Oceanogr. 11, 1443-1451.

Pacanowski, R.C., Dixon, K., Rosati, A., 1991. The GFDL Modular Ocean Model Users Guide, version 1.0. GFDL Ocean Group Tech. Rep., No 2, 176 pp.

Rachev, N.H., Stanev, E.V., 1997. Eddy processes in semi-en- 
closed seas. A case study for the Black Sea. J. Phys. Oceanogr. 27, 1581-1601.

Roache, P.J., 1976. Computational Fluid Dynamics. Hermosa Publishers, Albuquerque, NM, 446 pp.

Roache, P.J., 1995. Elliptic Marching Methods and Domain Decomposition. CRC Press, 190 pp.

Sanderson, B.G., 1998. Order and resolution for computational ocean dynamics. J. Phys. Oceanogr. 28, 1271-1286.

Sanderson, B.G., Brassington, G., 1998. Accuracy in the context of a control-volume model. Atmos.-Ocean 36 (4), 355-384.

Sheng, J., Wright, D.G., Greatbatch, R.J., Dietrich, D.E., 1998. CANDIE: a new version of the DieCAST ocean circulation model. J. Atmos. Ocean Technol. 15, 1414-1432.

Sokolova, E., Stanev, E., Yakubenko, V., Ovchinnikov, I., Kosyan, R., 2001. Synoptic variability in the Black Sea. Analysis of hydrographic survey and altimeter data. J. Mar. Sys. 31, 45-63 (this issue).

Sorkina, A.I. (Ed.), Reference Book on the Black Sea Climate. Gydrometeoizdat, Moscow, 406 pp. (in Russian).

Stanev, E.V., 1990. On the mechanisms of the Black Sea circulation. Earth-Sci. Rev. 28, 285-319.

Stanev, E.V., Beckers, J.M., 1999. Numerical simulations of seasonal and interannual variability of the Black Sea thermohaline circulation. J. Mar. Sys. 22, 241-267.

Stanev, E.V., Rachev, N.H., 1999. Numerical study on the planetary Rossby waves in the Black Sea. J. Mar. Sys. 21, 283-306.

Stanev, E.V., Staneva, J.V., 2000. The impact of the baroclinic eddies and basin oscillations on the transitions between differ- ent quasi-stable states of the Black Sea circulation. J. Mar. Sys. 24 (1-3), 3-26.

Stanev, E.V., Staneva, J.V., Roussenov, V.M., 1997. On the Black Sea water mass formation. Model sensitivity study to atmospheric forcing and parameterization of some physical processes. J. Mar. Sys. 13, 245-272.

Stanev, E.V., Le Traon, P.-Y., Peneva, E.L., 2000. Sea level variations and their dependency on meteorological and hydrological forcing. Analysis of altimeter and surface data for the Black Sea. J. Geophys. Res. 105 (C7), 17203-17216.

Stanev, E.V., Beckers, J.M., Lancelot, Ch., Le Traon, P.Y., Staneva, J.V., Peneva, E.L., Gregoire, M., 2001. Coastal-open ocean exchange. Black Sea examples from survey, satellite data and modeling. Estuarine Coast Shelf Sci., Supplementary issue (in press).

Staneva, J.V., Stanev, E.V., 1997. Cold intermediate water formation in the Black Sea. Analysis of numerical model simulations. In: Ozsoy, E., Mikaelyan, A. (Eds.), Sensitivity to Change: Black Sea, Baltic Sea and North Sea. NATO Ser. Kluwer Academic Publishers, Dordrecht, pp. 375-393.

Staneva, J.V., Stanev, E.V., 1998. Oceanic response to atmospheric forcing derived from different climatic data sets. Intercomparison study for the Black Sea. Oceanol. Acta 21, 393 417.

Sur, H.I., Ozsoy, E., Ilyin, Y.P., Unluata, U., 1994. Boundary current instabilities, upwelling, shelf mixing and eutrophication processes in the Black Sea. Progr. Oceanogr. 23, 249-302. 